\title{
Blueprint for an automated specific decision support system for countering anthelmintic resistance in Haemonchus spp. at farm level
}

\author{
J.A. van Wyk*, D.P. Reynecke
}

Department of Veterinary Tropical Diseases, Faculty of Veterinary Science, University of Pretoria, Private Bag X04, 0110 Onderstepoort, South Africa. E-mail: jan.vanwyk@up.ac.za

*Corresponding author. Tel. +27-12-529-8380; fax +27-12-529-8312

E-mail address: jan.vanwyk@up.ac.za (J.A.van Wyk)

\section{Abstract}

This article is the first of a series aimed at developing specific decision-support software for on-farm optimisation of sustainable integrated management of haemonchosis. It contains a concept framework for such a system for use by farmers and/or their advisors but, as reported in the series, only the first steps have been taken on the road to achieving this goal.

Anthelmintic resistance has reached such levels of prevalence and intensity that recently it evoked the comment that for small ruminants the final phase of resistance was being entered, without effective chemotherapeutic agents on some farms with which to control worms at a level commensurate with profitable animal production. In addition, in the case of cattle, a recent survey in New Zealand showed $92 \%$ of worm populations to be resistant to at least one anthelmintic group.

Ironically, new technology, such as the $\mathrm{FAMACHA}^{\circledR}$ system which was devised for sustainable management of haemonchosis, is at present being adopted relatively slowly by the majority of farmers and it is suggested that an important reason for this is the complexity of integration of new methods with epidemiological factors. The alternatives to the simple drenching programmes of the past are not only more difficult to manage, but are also more labour intensive. The problem is further complicated by a progressive 
global shortage of persons with the necessary experience to train farmers in the new methods.

The opinion is advanced that only computerised, automated decision support software can optimise the integration of the range of factors (such as rainfall, temperature, host age and reproductive status, pasture type, history of host and pasture infection, and anthelmintic formulation) for more sustainable worm management than is obtainable with present methods. Other than the conventional method (in which prospective analysis of laboratory and other data is mainly used to suggest when strategic prophylactic drenching of all animals for preventing excessive helminthosis should be conducted during the relevant worm season), the computer model being proposed is to be based on targeted selective treatment, supported by progressive periodic retrospective analysis of clinical data of a given worm season.

It is emphasised that, in order not to repeat the mistakes of the past, such an automated support system should ideally be developed urgently in a attempt to engineer greater sustainability of any unrelated new anthelmintics which may reach the market.

Keywords: Worm management model; Automated decision support; Gastrointestinal nematode; Anthelmintic resistance; Haemonchus spp.

\section{Introduction}

Anthelmintic resistance (AR) of certain gastrointestinal parasites of sheep is close to being intractable on a growing number of farms throughout the world, and while methods with potential for considerably delaying its further development are progressively becoming available, their on-farm application is proving to be problematical. 
In 1985 and 1990 Van Wyk warned that it was possible that AR would involve all the available anthelmintic compounds to such an extent that eventually no effective remedies would be available with which to control gastrointestinal helminths in domesticated ruminants, unless anthelmintics were applied in a more sustainable manner. In 1997 this possibility became a reality when the first case of resistance of a single worm population was reported to compounds from all five of the anthelmintic activity groups available at the time for use against gastrointestinal nematodes in sheep and cattle (Van Wyk et al., 1997). Included among these compounds were the first reported cases of resistance to nitroxynil and disophenol. Today, even overt resistance to moxidectin, previously only marginally affected even after resistance to other macrocyclic lactone compounds, particularly ivermectin, had become common-place, has developed not only when administered alone, but also when used together with other previously highly effective compounds (Table 1) (C.S. Sotomaior, personal communication, 2006).

TABLE 1. Worm populations found in a faecal egg count reduction test survey in Paraná State, Brazil, to be less than $80 \%$ susceptible to moxidectin drenched either alone or together with other compounds (Sotomaior et al., personal communication, 2006)

\begin{tabular}{|l|c|c|}
\hline \multicolumn{1}{|c|}{ Worm populations } & Moxidectin & Moxidectin plus other $^{1}$ \\
\hline Less than $80 \%$ susceptible & 21 & 6 \\
Less than $30 \%$ susceptible & 6 & 0 \\
Mean & $0-74 \%$ & $55 \%$ \\
Range & & $30-77 \%$ \\
\hline
\end{tabular}

${ }^{1}$ Moxidectin + Closantel and/or Moxidectin + Nitroxynil 
While drug resistance was previously uncommon in the worms of cattle, they are following suit. For instance resistance to ivermectin was present on 55\% of 69 farms surveyed in Argentina (Caracostantogolo et al., 2005) and on 92\% of 62 farms in New Zealand (Waghorn et al., 2006). In addition, resistance to levamisole and/or albendazole was detected on $76 \%$ of these New Zealand farms. Thus it seems likely, as already voiced by Waller $(1997 ; 2003)$ that AR in the worms of cattle would follow much the same pattern as that in small ruminants, with unrelated new compounds included in time, unless the mistakes of the past are avoided.

This paper is intended as an introduction to a series aimed at the development of software for an automated specific decision-support software system (DECSUP) for optimal sustainable integrated worm management.

\section{Background to development of the envisaged software}

In reaction to escalating anthelmintic resistance, various countermeasures which are based on methods of sustainable Integrated Parasite Management (sIPM), have been and continue to be developed for more sustainable worm management. However, these are more complicated to apply than conventional drenching programmes (Van Wyk, 2003; 2006; Van Wyk et al., 2006). This situation is aggravated by a world-wide reduction in the numbers of knowledgeable trainers of trainers and extension personnel well enough versed in modern approaches to worm management to give the necessary day-to-day support to farmers. 


\subsection{Refugia and Targeted Selective Treatment (TST)}

Helminths which escape any given control measure, are said to be in refugia. Examples are those stages in the life cycle of the worm or worms concerned that are either in untreated hosts, or on pasture outside their hosts, on pasture, when the hosts are drenched (Martin et al., 1981; Martin, 1989; Van Wyk 2001). As a result, the stages which escape selection for AR genetically dilute resistance genes by interbreeding when adult, with the progeny of survivors from treated animals.

One of the most effective ways of obtaining relatively large numbers of worms in refugia is selectively to treat only clinically affected animals, i.e. a system of targeted selective treatment (TST), in which those that are untreated void unselected parasites onto pasture. As worm burdens are markedly overdispersed in a given flock or herd (Barger 1985), it is uncommon for any but a small minority of animals to be unable to withstand the effect of worm infection without anthelmintic treatment. Previously, this phenomenon could not be utilised in practice, since there was no practicable method for on-farm identification of the most severely affected animals, which required treatment, while the rest were safely left untreated. In addition, laboratory analysis was not feasible, since at the height of the worm season every animal should be tested at relatively short intervals to prevent losses in production or even deaths. For instance, in sheep with severe $H$. contortus challenge, Malan et al. (2001) recorded a drop of up to seven percentage points in haematocrit readings within seven days in a few sheep, or put in another way, a sheep which is apparently coping well with relatively mild anaemia, can develop terminal anaemia within a week.

It was only after Malan and Van Wyk (1992) had devised a system to clinically grade and classify the anaemia of haemonchosis that TST became a practical consideration. This 
system was subsequently developed by a South African team into the FAMACHA ${ }^{\odot}$ system (Bath et al., 1996; 2001; Van Wyk and Bath, 2002), which comprised the use of a colour chart depicting the ocular mucous membranes of unaffected sheep compared to those of sheep suffering from various degrees of anaemia (i.e. from the deep red of a healthy animal, through different shades of pink to the practically white of a terminally anaemic animal). Highly significant levels of correlation have been demonstrated between the results of this FAMACHA $^{\odot}$ clinical classification of anaemia and microhaematocrit determination, the laboratory gold standard used as a control (Van Wyk and Bath, 2002; Reynecke et al., 2009a; Riley and Van Wyk, 2009). When the severely anaemic animals are effectively dewormed, the small numbers of resistant helminths which survive the treatment are genetically swamped by overwhelming numbers of the offspring of undiminished numbers of unselected worms originating from untreated hosts. Hence selection for anthelmintic resistance is greatly reduced, with much improved sustainability of drug usage before AR sets in.

The FAMACHA ${ }^{\odot}$ method, unfortunately, has two main disadvantages: (i) it is applicable only to haematophagous worm species, and (ii) it is relatively labour-intensive. Concerning the latter, the often "explosive" nature of outbreaks of haemonchosis with consequent rapid development of anaemia, led Van Wyk and Bath (2002) to recommend weekly evaluation of all sheep on farms concerned at the peak of the worm season, and a reduced evaluation rate at other times when risks of infection are lower. However, as discussed below, at present it is not clear when such frequent evaluation should commence, for how long it should continue, or whether it is indeed essential that all classes of sheep, or even all individuals within a given class or flock, need to be examined on every occasion. In an attempt to address these issues, an experimental stochastic simulation model, which simulates worm burdens in relation to blood haemoglobin levels 
and live body weight, is also being evaluated in this series (Reynecke et al., 2009b);

present indications are that it could be useful for risk reduction/aversion as regards setting of intervals between FAMACHA ${ }^{\circledR}$ evaluation events.

\subsection{Targeted Selective Treatment (TST) versus Targeted Treatment (TT)}

Recently, Kenyon et al. (2009), described what they called Targeted Treatment (TT), an approach to avoid the relatively large labour component of TST involved in frequent clinical evaluation of all animals in a given flock or herd. This TT approach entails drenching all animals when there are indications of considerable worm challenge of all animals in a given flock or herd, but in definite relation to sufficient worms in refugia at the time for the enhancement of the sustainability of the anthelmintics used.

\subsection{Complexity of optimal application of TST and TT}

The complexity of alternative methods of worm management is well illustrated by the example of a farmer wishing to apply the principle of refugia as a hedge against severe selection for anthelmintic resistance. If he wishes to drench all animals before a move to "clean" pasture on which there are few or no free-living stages of worms, then use of an ultra long-acting anthelmintic formulation or preparation (such as the latest formulations of ivermectin and moxidectin), applied even some months before the move, will almost certainly result in only selected (thus resistant) helminth ova being deposited on the new pasture, while a short-acting formulation of such a compound would have much less of a selective effect. Dozens of trade names of anthelmintics and various formulations of those which are presently available on the market confuse farmers, and specialist knowledge is required to be able to differentiate them. Similarly, a single drench of all animals at the 
time they are placed on crop aftermath (where there are generally practically no worms in refugia) and are then subsequently moved a few months later to rested pasture, will, despite the passage of time, be equivalent to an immediate drench-all-and-move procedure.

\subsection{Automated specific decision support based on clinical evaluation and Targeted}

\section{Selective Treatment as a solution}

As suggested by Van Wyk $(2003 ; 2006)$ and Van Wyk et al. (2006), we propose that an electronic automation system could offer a solution to the problem of complexity, i.e. one that is so specific that it would lead the farmer in decisions such as the proportions of animals of each class to treat on day $\mathrm{X}$ on farm $\mathrm{Y}$ when animals are handled; how many of each class of animal to treat; which compounds to use/to avoid (e.g. due to AR); the interval before the animals concerned need to be examined again; and how optimally to integrate all factors with relevance to the farm and conditions at the time (sIPM). We consider that the technology required to make this possible is already available, even though perhaps not yet in a functional, integrated system.

Without expert knowledge in day-day decisions at farm level concerning such matters as (i) the susceptibility of worm population(s) to available anthelmintics; (ii) the relative susceptibility of the class of animal involved to worm challenge; (iii) the level of worm infection in the animals; (iv) the likelihood of escalating worm challenge immediately following a given animal evaluation occasion; and (v) the relationships between active ingredients and the formulation characteristics of various compounds, it is virtually impossible for farmers, or even many/most(?) of their advisors, optimally to integrate worm management practices into a sustainable whole. However, we consider that an 
expert could be well supported by such a decision-support tool to enable him/her to serve a much larger number of farmers and/or their advisors, and the model could also be used in the specialised training of parasitologists, veterinarians, veterinary students and extension workers.

Various worm management models have been developed in the past, including those of Gettinby (1989), Echevarria et al. (1993), Smith and Grenfell (1994) and Learmount et al. (2006) which have widely differing objectives. However, use of practically all of them was dependent on extensive on-going laboratory analysis, few were adapted for on-farm application, and none were based on selective treatment of animals. Furthermore, the primary objectives of many of them were to predict the timing of the peak worm challenge for a given season, and to forestall this through prophylactic or strategic drenching of all animals. While this approach is uncomplicated, can be highly effective and is thus popular with farmers, it does select severely for worm resistance, especially if the animals are moved to "safe" or "clean" (i.e. practically worm-free) pasture after treatment (Martin et al., 1981; Martin, 1989; Van Wyk, 2001). Nevertheless, three recent models merit special mention, having been developed specifically for application by farmers. "WormBoss" ( (www.wormwijzer.nl) plus "Parasietenwijzer" (www.parasietenwijzer.nl) of The Netherlands comprise guidelines for farmers to be able to make decisions concerning the application of specific worm control measures. However, having been developed primarily for regions with more temperate climates and generally lower availability of labour than in most countries in the tropics and subtropics where Haemonchus spp. predominate, they are not based on TST as regards identification of individual animals within a mob that are unable to withstand severe worm challenge. "Wormwijzer" recommends leaving a relatively small proportion of animals in good condition within a 
given mob undrenched in order to enable unselected worms to compete genetically in refugia with the progeny of those which resist the anthelmintic(s) used in treated hosts. Especially in tropical/subtropical regions this would put these untreated animals at risk of death from unobtrusive anaemia, since it is of common occurrence for animals in good condition suddenly to die from haemonchosis “...without showing much more than anaemia and hydraemia” (Mönnig, 1950). Pastures and farm management systems probably also differ to a larger extent from place to place in the less temperate regions than, for instance, in The Netherlands. Hence, for these warmer regions an automated system needs to include more specific sources of variation, with the emphasis on

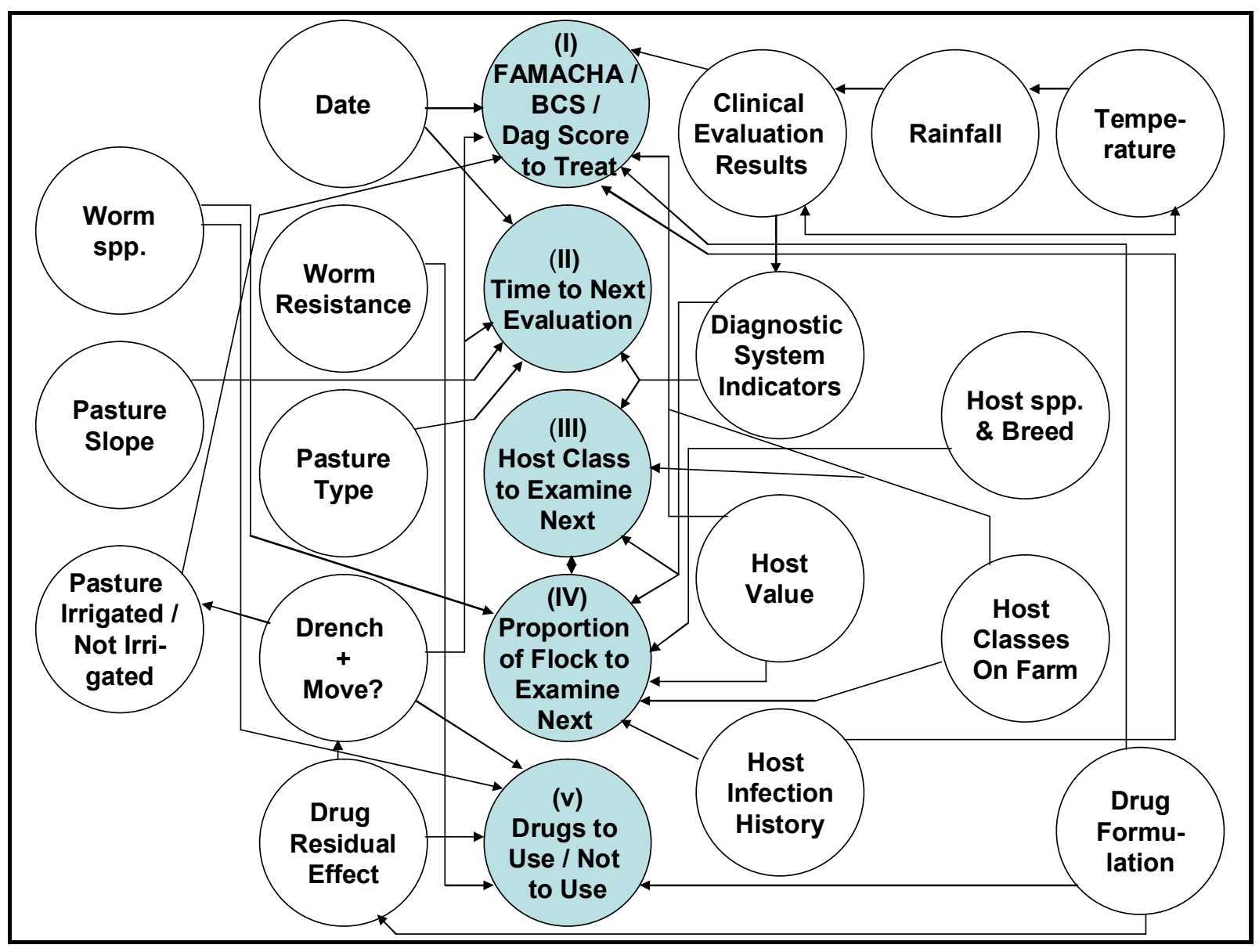

Fig. 1. Automated decision support model: Schematic presentation of some factors to consider in arriving at decisions, and their interactions with one another and the envisaged outputs, represented by the shaded circles (i) to (v) 
haemonchosis, e.g. for identifying relatively susceptible individuals and for reducing the present labour component of TST.

\section{Decision-support software (DECSUP) development}

It is essential that farmers appreciate that optimum, not maximum, production is the prerequisite for sIPM (Van Wyk, 2006). In general, if any animal production system is so far removed from Nature that it can only maintain profitable animal production through heavy dependence on chemicals to the exclusion of alternative methods, then a change to a more sustainable farming system should seriously be considered (Malan et al., 1997). It should also be accepted that the very nature of such production systems typically dictates that they be maintained at an unstable equilibrium between hosts and parasites. Another positive advantage of selective treatment is therefore that the production system will be allowed to "equilibrate" itself at a more stable, and thus a theoretically more sustainable level. Increased sustainability of worm management and labour saving would perforce need to be the principal aims of the intended model.

\subsection{Decision system inputs}

As set out more fully below, in the envisaged DECSUP system a variety of inputs are to be used to compute the five different outputs depicted in Fig. 1. In order to provide a functional model, only the inputs regarded as crucial (for instance rainfall, retrospective analysis of $\mathrm{FAMACHA}^{\odot}$ data sets for a given worm season, and the list of anthelmintics to be recommended for a specific situation according to active ingredient and formulation) are initially to be included as separately computed model components. Indeed, some of 
these have been developed and are reported on in the present series (Reynecke et al., 2009a; 2009b; Riley and Van Wyk, 2009). The other inputs will initially be based on “expert opinion", i.e. judgment on a 1-4 or 5 plus basis. With regard to the latter, farmers are generally adept at step-wise (Likert-scale type) ordination, which could provide estimates for factors such as average temperature at a given time in relation to long-term averages, and the character of rainfall (whether precipitation was mainly soft and penetrating, or in torrents - see below). Indeed, it is likely that, even in the "final" version of such a model, provision will still have to be made for expert opinion in resource-poor communities where some specific data, such as rainfall, may not be available.

\subsection{DECSUP outputs}

The planned outputs of the software system (Fig. 1) are recommendations for (i) FAMACHA $^{\odot}$, Body Condition and Dag scoring categories to treat; (ii) the interval (time) to the next evaluation; (iii) the host classes to examine next; (iv) the proportion of the most susceptible flock to examine; and (v) the anthelmintics to use (e.g. in relation to predominant worm genera) or to avoid. Specifically, in the case of the proportion of the most susceptible flock or mob to examine (information which would have been gleaned from multiple iterations of a worm-burden model - Reynecke et al., 2009b), a straightforward application of a sample size calculation would be carried out. Implicit in this type of application, however, will be the need to have at least some estimate, for instance using FAMACHA $^{\odot}$ evaluation, of the prevalence of disease. For a helminth disease such as haemonchosis, this would be expressed as the proportion of animals deemed to be testpositive (i.e. not coping with their worm burden, and thus qualifying as requiring 
treatment) under the assumption that virtually every animal is infected (Gordon, 1981), but that not all animals need to be treated.

In the case of the FAMACHA $^{\odot}$ clinical test for anaemia, the expected prevalence could be related to that obtained from a previous sampling occasion and this value modified according to the perceived epidemiological risk in the intervening period. Each of these outputs would be modelled individually (by simulation, if necessary), taking into consideration the various inputs which have an important influence on its outcome. For instance, a decision in Output (i) in Fig. 1 on the FAMACHA ${ }^{\odot}$ category to treat on a given farm would depend on various combinations of test sensitivity and specificity (Reynecke et al., 2009a; 2009c), Receiver Operating Characteristic curve (ROC) analysis (Greiner et al., 2000; Reynecke et al., 2009c), determination of comparative susceptibility between different mobs/classes of animal, an evaluation of rainfall and an estimate of the prevalence of animals requiring treatment.

By stepwise inclusion of other factors which may have a meaningful effect (e.g. host susceptibility - Fig. 1), the risks involved in each recommendation can be estimated. In this way, a farmer could be led by the model output to select different intervals between evaluation events, as well as different treatment thresholds according to "acceptable" risk, for instance according to the value of the animals concerned and the relative susceptibility according to host class. It is envisaged that "weights" would have to be allocated to each relevant factor in Fig. 1, in relation to its importance to every individual recommendation. In other words, it will be necessary to model not only individual inputs, but also the level of contribution of each input to every separate recommendation. 


\subsection{Clinical evaluation systems other than FAMACHA ${ }^{\circledR}$}

Note that in Output (i) in Fig. 1 provision is made also for inclusion of other clinical evaluation data, such as Body Condition (BCS) and Dag scoring for non-haematophagous worm species, if found to be practicable. These indicators have not as yet been fieldevaluated nearly to the same extent as the FAMACHA $^{\odot}$ system for practicability of use in TST, but present indications are that they could also be useful in both sheep and goats (Van Wyk and Bath, 2002; Mahieu et al., 2007; Kenyon et al., 2009), especially for farmers in developing countries, with no convenient access to laboratory sample analysis. For use of BCS as a treatment indicator, however, it would be crucially important from time to time to be able to interpret the accuracy of clinical diagnosis against a gold standard such as weight and/or average daily gain. Recent developments in the field of application of Receiver Operating Characteristic curve (ROC) analysis hold promise in this regard (Greiner et al., 2000). ROC analysis has been successfully applied to rating systems to (i) determine how effective a given clinical test is in differentiating between "healthy" individuals (i.e. below a given threshold) from "diseased" (threshold-exceeding or needing treatment) individuals; (ii) to obtain an optimised trade-off between test sensitivity and specificity; and (iii) to compute likelihood ratios, which are then to be used for making statistically relevant informed decisions on selection of treatment thresholds. However, it is obvious that much more work needs to be done on these other methods and this can proceed concurrently with development of the DECSUP software, in much the same way that the FAMACHA $^{\circledR}$ test was developed and validated. 


\section{4 Retrospective analysis of clinical evaluation data}

With use of FAMACHA ${ }^{\circledR}$ and other methods of TST a series of data sets accumulates per flock over every worm season, for instance as depicted in Fig. 2. Using such a data set, retrospective analysis with risk simulation models (Reynecke et al., 2009b) and Receiver Operating Characteristic (ROC) curve analysis (Reynecke et al., 2009c), can be used to adjust inclusion of more or fewer FAMACHA $^{\circledR}$ categories for treatment, in turn to obtain a balance between labour inputs, risk levels and refugia. Levels of refugia can be controlled through adjustment in FAMACHA $^{\complement}$ categories to treat. For instance, while the general recommendation has been routinely to treat all sheep and goats in FAMACHA ${ }^{\odot}$ categories 3-5 (Van Wyk and Bath, 2002), this can be adjusted at the peak of the worm season to include animals in category 2 , or even, if this adjustment does not succeed in reversing the tendency to increasing levels of anaemia, also category 1 (i.e. to treat all the animals)

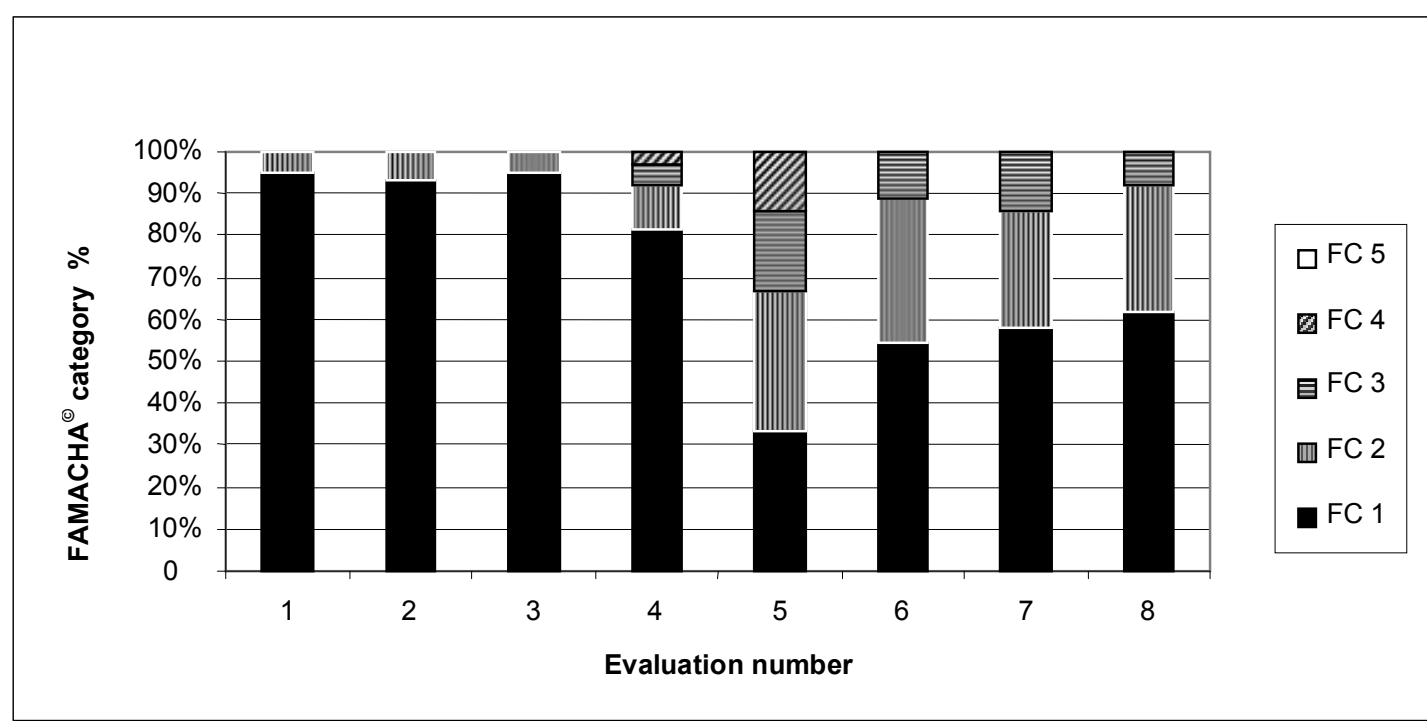

FIG. 2. Example of FAMACHA ${ }^{\odot}$ results for eight evaluations over a Haemonchus season in South Africa for a group of 130 ewes (FC - FAMACHA ${ }^{\odot}$ category $1-5$ FAMACHA $^{\odot}$ category 5 not present). 


\subsection{Factors to consider and practicability of inclusion of multiples of them}

If all the factors discussed individually below, and shown in Fig 1, were to be included in every aspect of the envisaged software model, it could conceivably require so many computer "mouse clicks" as to be impractical for routine use by farmers who are either not well versed in helminth management, or are not prepared for the necessary input required for a superior level of decision output. To this end, the model is to be designed for application at different levels of complexity, for instance a "basic level" on one hand, intended for the commercial or even the resource-poor farmer whose sheep are not individually identified, an "advanced level" for the stud farmer who wishes to apply the system for breeding resistant/resilient sheep (Riley and Van Wyk, 2009) and intermediate levels as required. The intention is to get the system functional at the basic level and then to expand it stepwise thereafter.

\subsection{Farm location and predominant worm species}

In a country such as South Africa with widely differing climatic zones - from a Mediterranean-type climate to subtropics - and where numerous, widely disseminated field trials have been conducted, farm location gives a good indication of the rainfall patterns and amounts, as well as the principal worm species and their seasonal cycling to be expected on a given farm (Horak, 1981). It can also be an aid for judging the likelihood of the presence of AR on the farm. For instance, in communal farming regions in South Africa, where resource-poor farmers predominate, there is generally less use of anthelmintics than on commercial farms, and consequently less anthelmintic resistance (Van Wyk et al., 1999; Vatta and Lindberg, 2006). Thus farm location can be included as 
a factor, for instance as an indication of worm species to be expected and the likelihood of success with application of a clinical method such as FAMACHA $^{\odot}$ for routine worm management.

\subsection{Rainfall amount and character}

As is well known, rainfall is of prime importance for gastrointestinal worm development, not only for development and survival of free-living stages of worms, but also for their translocation from faecal pats or pellets onto the pasture. Consequently, rainfall has been taken into consideration in a variety of ways in most investigations on worm epidemiology, for instance in the form of monthly total rainfall figures or of bioclimatographs which indicate suitable periods for development of the various worm species over the course of a calendar year according to rainfall and temperature data (Gordon, 1948; Levine, 1980). However, since so many factors impact on worm development, bioclimatographs and their equivalents can at best only be a rough guide to the levels of worm challenge to be expected at any given time; they are not of use for identifying individual animals which are not coping with worm challenge, without which it is of no practical significance for TST.

A complicating factor as regards accurate evaluation of the effect of rainfall on subsequent development of verminosis in animals, is that in effect a two-step process is involved initially before larvae become available on pasture. Firstly, there is the effect of weather at the time of deposition of faeces on the degree of development from unembrionated egg to L3, and secondly, on the softening effect of rainfall on the crust of dried faeces, to allow L3 to escape onto pasture. Add to this the almost limitless 
combinations of duration and amount of rainfall, with accompanying variation in time of cloud cover.

Conventionally, papers on gastrointestinal nematode epidemiology list only monthly rainfall, without any indication of its daily amount and character in relation to subsequent worm proliferation. Nevertheless, rainfall is known to be an independent dose variable (Rossiter, 1961; Thomas, 1968; Horak and Louw, 1977; McCulloch et al., 1984; Ikeme et al., 1987; O'Connor et al., 2007). With the use of a mathematical model simulating the dynamics of Teladorsagia circumcincta, Paton et al. (1984) found that the "moisture" status of pasture on which faeces were deposited was important for predicting the development and survival of pre-infective larvae. Besier and Dunsmore (1993) recovered a greater percentage of subsequent infective larvae from pasture when a total of $8 \mathrm{~mm}$ of rain was distributed over 4 consecutive days from the day of deposition of $H$. contortus ova in faeces on the pasture, than when $26 \mathrm{~mm}$ of rain fell on the day of deposition. The matter was also reviewed by Levine (1980), principally in relation to the balance of precipitation and evapotranspiration. For instance, he considered the respective potential transmission period of Haemonchus on one hand and that of Trichostrongylus / Teladorsagia on the other to be $15-37^{\circ} \mathrm{C}$ and $6-20^{\circ} \mathrm{C}$, combined with "soil water deficiency" (precipitation minus evapotranspiration) of not more than $200 \mathrm{~mm}$ for both groupings. However, in addition to such factors which have received considerable attention, there is likely to be a threshold amount of rainfall that will be required at any given time before faecal pats or pellets will be sufficiently softened to enable infective larvae to escape onto pasture and thus become available to their animal hosts. For instance, if a total of $25 \mathrm{~mm}$ of rain were to fall over a period of an hour or two it may conceivably be sufficient to soften somewhat moist faecal pats or pellets, but perhaps not those that have been exposed to dry conditions for some days or weeks. In contrast, if the 
same amount of rain were to fall within minutes, run-off may be so fast that the faeces are not softened sufficiently to allow for larval translocation to pasture, and on a hillside slope much of the faeces may be washed away into streams or distant pools, with the result that the contained worm larvae are lost to the hosts from which they originated. This issue of softening of the faeces was investigated to some extent through use of different combinations of amount and spacing of bouts of simulated rainfall by O'Connor et al. (2007), but results were unequivocal, probably because of very poor translation of L3 to pasture in their experiments.

The issue of the spread of rainfall was addressed by McCulloch et al. (1984) who stated that daily, weekly and monthly rainfall figures gave no real indication of pasture "wetness". These authors referred to "dangerous eight-week rainfall periods", during which at least five of the eight weeks exhibited the estimated minimum four-week rainfall requirement for elevated pasture infectivity.

More recently, Reynecke (2007) found that on a farm where the FAMACHA ${ }^{\circledR}$ system of TST had been applied for more than six years, Shannon's entropy model (1948) gave encouraging results concerning the indication of imminent peaks of worm challenge. However, these initial results should be pursued on farms under a variety of conditions of climate and farm management systems. An important consideration is the extent to which the amount and nature of the rainfall and faeces may affect the threshold amount/distribution of precipitation required to enable larvae to escape from dry faecal deposits. In addition, it also seems likely that satellite imagery will be an aid for evaluating the effect of rainfall amount and character in relation to levels of worm infection and the proportions of animals that require treatment in any TST worm management system in relation to either waxing or waning worm burdens. Another consideration is that farmers are generally able to estimate both amount and character of 
rainfall without having recourse to specific rainfall figures, and that such estimates could be included as an alternative "expert opinion" option in the DECSUP model, particularly in resource-poor farming systems.

\subsection{Environmental temperature}

Environmental temperature is practically on a par with rainfall with regard to its influence on the seasonal cycling of different species of helminths (Veglia, 1915; Levine, 1980; Gordon, 1981). At lower temperatures the development of worm ova is considerably delayed or ceases and they may even die (Rose, 1970). However, rising temperatures during spring and summer progressively speed up the development of larvae in worm eggs until they hatch in an intensive wave, the so-called concertina effect (Rose, 1970). In general, once the eggs have hatched, the emerged larvae, after developing to the infective third stage (L3), are less susceptible to extremes of environmental temperature (Rose, 1970). As in the case of rainfall, it is probable that most farmers are able to estimate the temperature sufficiently accurately, on a 1-5-plus scale, to be used in DECSUP. Another possibility is to use regional data from weather stations if they are situated relatively close to the farm concerned, since environmental temperature varies less from farm to farm than rainfall does. Thus temperature should be evaluated for inclusion as a factor in the model.

\subsection{Animal host species and breed}

FAMACHA $^{\odot}$ has also been found to be a useful tool for diagnosing the extent of the anaemia in cases of trypanosomosis in cattle (Grace et al., 2007), but the blueprint 
described here is intended primarily for use in small ruminants, since routine application of FAMACHA $^{\odot}$ is physically much easier in small than in large ruminants and the former are generally less able to manage unaided, i.e. unless treated, in the face of severe worm challenge. However, not only the species, but also the sex, class and history of animals are of importance in the development of automated decision support systems (Malan et al., 2001).

Over and above host species, different host breeds can be important in the magnitude of worm infection in sheep (Baker et al., 1999) and goats, e.g. in South Africa Angora goats are more susceptible to their deleterious effects than are the indigenous goats. However, for the majority of breeds there is more variation within a given breed than between different breeds (Eady et al., 1996). Hence with few exceptions there will be little, if any, need to include differences between breeds in DECSUP evaluations.

\subsection{Host class in relation to treatment and intervals between clinical evaluations}

Initial trials designed to test the $\mathrm{FAMACHA}^{(}$principle of clinical evaluation of the anaemia of haemonchosis according to the colour of the ocular mucous membranes, illustrated clearly that while $83 \%$ of dry, non-pregnant ewes were able to withstand severe Haemonchus challenge unaided, i.e. without having to be drenched, only $71 \%$ of heavily pregnant and $45 \%$ of lactating ewes in the same flock were able to do so (Malan et al., 2001). This phenomenon has important implications not only for decision support modelling, but also for labour saving in TST application.

In early TST trials and field investigations all classes of sheep were handled similarly as regards intervals between their clinical evaluations and the FAMACHA ${ }^{\odot}$ classes to treat (Malan et al., 2001; Van Wyk et al., 2001; Van Wyk and Bath, 2002). Instead, the 
clear-cut differences in susceptibility of the different classes hold the potential that much labour can be saved by setting intervals between clinical evaluations per ecological unit (e.g. pastures on predominantly flat, versus those on sloping terrain) according to the most susceptible flocks and by examining only these until there are indications of mounting worm challenge. Only at that stage, other less susceptible flocks maintained under similar conditions could be included also. As a further labour-saving device, only a sub-sample of the most susceptible flock can be examined initially after the recommended interval, either by random selection, or from the rear of a flock that is mustered over some distance to handling pens. From the results obtained (i.e. average state of anaemia in the subsample of sheep evaluated), further advice is then to be generated in DECSUP on whether or not entire flocks should be evaluated, as well as the $\mathrm{FAMACHA}^{\odot}$ categories to treat in order to manage worm burdens between pre-determined levels to prevent losses.

\subsection{Host age}

It is well known that young lambs and kids up to approximately eight months of age are immunologically compromised as regards the development of resistance to worm challenge (Gordon, 1981). However, there is also an additional stumbling block; farmers are reluctant to handle such young lambs at the relatively short intervals required at the peak of the Haemonchus season to prevent losses from haemonchosis in them. Allowance has therefore to be made for this in DECSUP. A possible solution is for the model to generate a recommendation that all suckling lambs should be treated when severe worm challenge is likely, or to examine only a few of the lambs and to treat all if the proportion of Class 1 animals in the aliquot is lower than, say, $80 \%$ or $90 \%$. Such treatment of lambs 
should have but little effect on selection for AR, on condition that their mothers are not all treated at the same time and can therefore maintain worms in refugia.

\subsection{Host value and special circumstances}

The value of the animals merits special consideration in DECSUP when balancing risk with labour-saving in relation to intervals between clinical evaluations of a given flock. In general, stud animals are more valuable than so-called commercial sheep, and, as on experimental farms, farmers of the former category are more inclined to drench them excessively, with resultant severe selection for AR (Van Wyk et al., 1991). This phenomenon therefore also requires special attention in DECSUP in order to emphasise testing for worm resistance even more strongly than is generally the case. Host value can be allowed for, either by reducing intervals between evaluations, or by treating more FAMACHA $^{\odot}$ categories than in the case of commercial animals, with due consideration of the dangers of selecting for AR by excessive drenching. On the other hand, such animals should not be molly-coddled; stud animals should be particularly robust under conditions of severe worm challenge. An outstanding example is the Rylington Merino stud in WA, Australia (Karlsson and Greeff, 2006), in which case continual selection for the ability to withstand severe worm challenge has led over some years to a stud that now requires almost no routine anthelmintic treatment.

\subsection{Pastures}

Pasture type plays a crucial role in the epidemiology of gastrointestinal helminth infection which necessitates taking additional factors into account in models aimed at 
specific automated decision support. The greater the number of edible bushes, shrubs and trees there are on a given pasture, the more animals will browse and the lower the buildup of worm infections that is to be expected (Horak et al., 1991; 2001). Some plants, e.g. the tannin-rich Lespedeza cuneata, have anthelmintic properties, although the most commonly observed effect of such bio-active plants is apparently a reduction in faecal worm egg counts (Hoste et al., 2006), and consistency of effect needs to be investigated further.

The more paddocks there are on a farm, the greater the scope for planning movements of animals in order to minimise the levels of worm challenge in a given worm season, provided that adequate records of flock movements are kept. A good example of this is the so-called "50-50" grazing system in South Africa (Kirkman and Moore, 1995) in which half the available grazing lies fallow for up to a year and, if there are adequate numbers of paddocks and both sheep and cattle, the sheep are moved to new pastures continuously ahead of the cattle and thus accumulate smaller worm burdens (Moore and Van Wyk, 1997). Similarly, intensive rotational grazing systems can have a considerable effect on the levels of worm infections (Healey et al., 2004). In both of the above examples, DECSUP can, with the passage of time, be programmed to allow the farmer who routinely enters details of the movements of his animals between paddocks, to vary intervals between evaluations in relation to the previous history of each paddock. And in the case of "clean" pastures (as in the 50-50 grazing system, above), the animals can first be moved without having been drenched, and then treated once "sufficient" numbers of unselected worm eggs have been deposited on the new pasture, i.e. the "Move-thenDrench" approach of Molento et al. (2004). Alternatively, if the move is necessitated by severe worm challenge on the current pastures, anaemic categories of animals can be treated at the time of the move to prevent losses in production. 


\subsection{Anthelmintics to use/to avoid (output (v) in Fig. 1)}

It is difficult to convince farmers to purchase anthelmintics according to the nature of their active ingredient(s) or more importantly their activity group(s), rather than on their trade names. In South Africa, even the listing of the activity group by number on the label of every registered anthelmintic preparation has apparently failed to overcome this problem. Consequently, virtually each and every sheep farmer has bred, over time, his or her own "brand" of anthelmintic resistance according to the drugs used and the circumstances under which they were used.

Formulations of any given anthelmintic compound differ to such an extent as to make blanket recommendations for their field use virtually impossible. As an example, use of a short-acting formulation of a given compound is preferable to that of a sustained-release formulation, such as the ultra-long acting moxidectin which was introduced to the market recently with a claim of being "highly effective" ( $\geq 95 \%)$ for a period of four months against $H$. contortus in South Africa. Given such a high level of efficacy after more than 120 days, selection against homozygous susceptible worms will continue for a considerably longer period than 6 months ${ }^{1}$. In other words, such worms will have virtually no chance of populating pastures during a given worm season, and will consequently be at a progressive numeric disadvantage in subsequent worm seasons.

\footnotetext{
${ }^{1} 95 \%$ effect at four months, plus "tail" period until efficacy has dropped to less than, say, $50 \%$
} 


\section{Effective technology transfer a necessity for countering AR}

If new technology is not accepted and applied by the end-user for whom it is intended, then it is not of much value. For instance, farmers who do not adopt sustainable methodology for worm control commonly select for severe AR of the worms in their sheep, with the result that animals are eventually sold at auctions and thus widely disseminate the genes concerned with helminth resistance (Van Wyk et al., 1989; Van Wyk, 1990). In addition, AR is introduced to a farm if animals bought at such an auction are drenched and then placed on "clean" pasture (Van Wyk, 2002).

\subsection{Technology transfer previously ineffective}

In both developing and developed countries unabated escalation of $\mathrm{AR}$, despite the availability of effective countermeasures (Van Wyk, 2001; Rhodes et al., 2006; Vatta and Lindberg, 2006), indicates that efforts at technology transfer to both farmers and scientists are probably inadequate. Regrettably, few of even the most basic factors required for sustainability have been adopted and are being applied by farmers despite decades of propagation by dedicated helminthologists. Only $31 \%$ of 80 farmers surveyed in New Zealand had ever had the efficacy of drugs they used monitored despite decades of strong emphasis by an excellent and very active extension team to have testing done regularly every few years (Lawrence et al., 2007). This is further illustrated by the fact that, despite an emphasis on various methods of IPM instead of dependence only on drenching for worm control, the majority of farmers still depend almost exclusively on chemical control. Commonly, their excuse for non-compliance is that losses in production could result if available alternatives were adopted. 


\subsection{Electronic approach has the necessary potential}

Van Wyk (2003; 2006) and Van Wyk et al. (2006) suggest that it is only through the use of computer generated, automated decision support which is specific to time and place, and contains definite recommendations on issues such as drugs to use/not to use, categories of animals to treat and intervals between clinical evaluations, that the present impasse concerning effective technology transfer to farm level can be solved. With this approach it is not necessary to train farmers or their advisors to the level of being able themselves to evaluate the complexities of the optimum period between treatment and movement of animals in accordance with the drug formulation used; in theory this can be managed by dedicated software. A big potential advantage of automated decision support is that, should it become necessary to make radical changes in current recommendations, such as no longer to emphasise routine alternation of anthelmintic activity groups (Van Wyk, 2001), little re-training will be required; the change can be made by merely adapting the software and by adding an information section for those who are well enough versed to detect the changes incorporated in the software (Van Wyk, 2006; Van Wyk et al., 2006).

Although a threat to the intended software could be that even an optimised system will perhaps not be widely adopted and applied by farmers, an immediate positive effect is that an effective system will be available to help those who are prepared to help themselves, while this is already becoming practically impossible at present, due to shortages of knowledgeable advisors.

Sufficient data have been generated in many countries to form the basis for the development of the relevant software and technology for on-farm application. These are presently available even for regions with practically no infrastructure other than access to 
electricity, and even this latter can be generated with the use of solar power. Most commercial farmers use computers daily for farm management decisions, and satellite transmission can be employed for resource-poor communal farmers where landlines are absent or not dependable. Communication between such farmers and their DECSUP advisors can, with few exceptions, occur via cellular (mobile) telephones. Technical ability to apply the FAMACHA $^{\odot}$ system is well-nigh independent of the level of education of the clinical evaluator (Van Wyk and Bath, 2002), and the per capita uptake of cellular telephones is generally higher in developing than in developed countries, with Africa being on the forefront of this trend (Anonymous, 2005; Johannes J. Britz, britz@uwm.edu, University of Wisconsin-Milwaukee, personal communication 2005). For instance, by 2001 cellular subscriber numbers in Africa had overtaken those of fixed lines, the first region of the world to achieve this (Anonymous, 2005). Furthermore, the effect of GSM ("Groupe Speciale Mobile", or wireless) technology is twice as large in developing nations as in their developed neighbours (Anonymous, 2005). Another advantage factor is that resource-poor farming communities are already largely centred around easily accessible farmers' committees.

\section{Discussion and conclusions}

In helminthology the $\mathrm{FAMACHA}^{\odot}$ method is applicable only to evaluating the extent of anaemia caused by haematophagous worm species such as $H$. contortus and, although not specifically tested, probably also that of the various hookworm and Fasciola spp. infections (Van Wyk and Bath, 2002). However, preliminary investigations indicate that clinical Body Condition Scoring may be of similar use for identifying animals severely infected with the so-called scours worms, Teladorsagia spp. and Trichostrongylus spp. 
(Van Wyk and Bath, 2002; Mahieu et al., 2007), albeit probably at lower levels of accuracy and usefulness (Kenyon et al., 2009), excepting perhaps for the resource-poor who for practical, logistical reasons have no alternative at present than routinely to drench all their animals, but for which they generally lack the necessary funding.

While much emphasis is placed in the article on development of alternative methods of technology transfer in reaction to a growing shortage of experts with the necessary experience for optimal application of sIPM, there is no doubt that such experts will remain of paramount importance for continuous software adaptation to local and changing conditions. On the other hand, it will greatly increase the capacity of those experts who are available, to serve larger numbers of farmers. In addition, as suggested by one of the unnamed reviewers of this article, an important role could be accorded to veterinarians and, in particular to parasitologists as regards use of the software for teaching farmers and students in veterinary or animal science. In this way a growing number of persons could be introduced to the intricacies of modern methods of sustainable worm management, to supplement and progressively replace experts retiring from this field.

Especially for the resource-poor, but also for commercial farmers, there is an urgent need for decision support software to neutralise the sales pressure of drug manufacturers/distributors and their representatives, in this way to avoid the mistakes being made in much of the commercial farming sector. No sooner do resource-poor farmers start to acquire some measure of financial stability and profitability with concomitant increased buying power, than marketers flock in with well-nigh the same messages and recommendations for excessive drenching, which have led to the practical demise of effective anthelmintics on many commercial farms (Van Wyk, 2006). 
TABLE 2 - Information to be considered for modelling and application of decision support software for sustainable, automated integrated worm management (sIPM)

\begin{tabular}{|c|c|c|c|}
\hline \multirow[t]{3}{*}{ (1) FARM LOCATION } & \multicolumn{3}{|l|}{ (a) Province } \\
\hline & \multicolumn{3}{|l|}{ (b) District } \\
\hline & \multicolumn{3}{|l|}{ (c) Grid reference } \\
\hline (2) DATE OF EVALUATION & \multicolumn{3}{|l|}{ Month } \\
\hline \multirow{2}{*}{ (3) RAINFALL } & \multicolumn{3}{|l|}{ (a) Long-term } \\
\hline & \multicolumn{3}{|l|}{ (b) Present } \\
\hline \multirow{2}{*}{ (4) TEMPERATURE (MIN/MAX) } & \multicolumn{3}{|l|}{ (a) Long-term } \\
\hline & \multicolumn{3}{|l|}{ (b) Present } \\
\hline \multirow{3}{*}{ (5) WORMS } & (a) Dominant spp. & \multicolumn{2}{|l|}{ Annual cycling } \\
\hline & \multirow[t]{2}{*}{ (b) Resistance history } & \multicolumn{2}{|c|}{ (i) Yes - Which anthelmintics affected } \\
\hline & & \multicolumn{2}{|c|}{ (ii) No -13} \\
\hline \multirow{8}{*}{ (6) DIAGNOSTICS } & \multirow[t]{2}{*}{ (a) FAMACHA ${ }^{\circ}$} & (i) Individual record & \\
\hline & & (ii) "Histograms" of & esults (Fig. 1) \\
\hline & (b) Haematocrits & & \\
\hline & (c) Worm egg counts & (i) Individual & \\
\hline & & (ii) Composite & \\
\hline & (d) Condition Scoring & (i) Individual & \\
\hline & & (ii) "Histograms" of & esults (Fig. 1) \\
\hline & (e) Host weights \& growth & & \\
\hline & (a) Breed & & \\
\hline (7) ANIMAL HOSTS & (b) Sex & & \\
\hline & (c) Class \& Age & & \\
\hline & (d) Identified or not & (i) Identified & (i) Indiv. Records \\
\hline & (d) Identified or not & (1) Identifled & ((ii)) Not indiv. Records \\
\hline & & (ii) Not identified & \\
\hline & (e) History & (i) Worm challenge & \\
\hline & & (ii) Vaccination & ((i)) Vaccine types \\
\hline & & & ((ii)) Dates \\
\hline & & (i) Yes - After wha & \\
\hline & (f) "Drench-all-and-move"? & (ii) No & \\
\hline (8) ANIMAI HUSBANDRY & (a) Animal nroduction classification & (i) Stud & (i) BLUP (see below) \\
\hline (8) ANIMAL HUSBANDRY & (a) Animal production classification & & ((ii)) Not BLUP(see below) \\
\hline & & (ii) Commercial & \\
\hline & & (iii) Resource-limite & \\
\hline & & (i) Breed own lambs & \\
\hline & (b) Animal production type & (ii) Lambs bought in & \\
\hline & & (iii) Speculator & \\
\hline & (c) Principal product & (i) Wool & \\
\hline & & (ii) Meat & \\
\hline & & (iii) Mixed & \\
\hline (9) PASTURES & (a) Natural & (i) Slope & (i) ) Valley \\
\hline (9) PASIURES & (a) Natural & & ((ii)) Hills/Mountains \\
\hline & & (ii) Acocks (1988) c c & tion \\
\hline & & (iii) Grazing history & (i) ) Present \\
\hline & & & ((ii)) Next paddock \\
\hline & (b) Improved & Crop species & ((i)) Irrigated \\
\hline & & & ((ii)) Not irrigated \\
\hline (10) ANTHEL MINTICS ONMARKFT & Tynes & (i) Trade names & \\
\hline 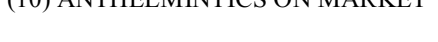 & & (ii) Formulations & (i) Oral \\
\hline & & & (iii) Injectable \\
\hline & & & ((iii)) Bolus \\
\hline & & (iii) Residual efficac & \\
\hline (11) MODFL JING and TESTING & & (i) $\mathrm{FAMACHA}^{\circ}$ & \\
\hline (11) MUDELLINU and IES IINU_- & Data required & (ii) Haematocrit & \\
\hline & & (iii) Condition Scori & \\
\hline & & (iv) Worm egg coun & \\
\hline & & (v) Host weights \& & \\
\hline & & (vi) Climate per farn & \\
\hline & & (vii) Best Linear Un & Production (BLUP) analysis \\
\hline
\end{tabular}


The principal advantage of using clinical methods of analysis such as FAMACHA $^{\odot}$ and Body Condition and Dag Scoring will be that, without the need for routine laboratory intervention, a series of results is obtained on-farm by the farmer himself as a given worm season progresses, on which to base risk-evaluated sIPM.

It is evident from the inclusion in Table 2 of the vaccination history of the animals concerned, that a decision support system, as envisaged, can be broadened for inclusion of other aspects, such as control of external parasites and certain infectious diseases. As a first step, however, the envisaged software, as described here, is aimed primarily at the control of internal parasites, principally Haemonchus sp., in small ruminants.

\section{Acknowledgments}

This work was done within the Framework Agreement between the Directorate General for Development Cooperation, Belgium, and the Institute of Tropical Medicine, Antwerpen (Belgium, under University of Pretoria Belgian Grant No. AG534), and with financial support from the EU "PARASOL" project (Food-CT-2005-022851). We also wish to make special mention of the unnamed reviewers, without whose detailed and constructive comments this paper would have lost much of its potential value. The helpful suggestions of Prof. Roy Tustin with the editing of the revised manuscript is gratefully acknowledged. 


\section{References}

Acocks, J.P.H., 1988. Veld Types of South Africa. In: Leistner, O.A., 1988. Memoirs of the Botanical Survey of South Africa. Pretoria: Botanical Research Institute.

Anonymous, 2005. Africa's cellphone revolution. Finance24 17 April 2005 - http //www.finance24.com)

Baker, R.L., Mwamachi, D. M., Audho, J. O., Aduda, E. O., Thorpe, W., 1999. Genetic resistance to gastro-intestinal nematode parasites in Red Maasai, Dorper and Red Maasai x Dorper ewes in the sub-humid tropics. Anim. Sci. 69, 335-344.

Barger, I.A., 1985. The statistical distribution of trichostrongylid nematodes in grazing lambs. Internat. J. Parasitol. 15, 645-649.

Bath, G.F., Hansen, J.W., Krecek, R.C., Van Wyk, J.A., Vatta, A.F., 2001. Sustainable approaches for managing haemonchosis in sheep and goats. Final Report of FAO Technical Cooperation Project No. TCP/SAF/8821(A).

Bath, G.F., Malan, F.S., Van Wyk, J.A., 1996. The FAMACHA ${ }^{\odot}$ ovine anaemia guide to assist with the control of haemonchosis. Proc. $7^{\text {th }}$ Ann. Congr. Livestock Hlth Prod. Group S. Afr. Vet. Ass., Port Elizabeth, 5-7.

Besier, R.B., Dunsmore, J.D., 1993. The ecology of Haemonchus contortus in a winter rainfall region in Australia: the development of eggs to infective larvae. Vet. Parasitol., 45, 275-292.

Caracostantogolo, J., Castaño, R., Cutullé, Ch., Cetrá, B., Lamberti, R., Olaechea, F., Ruiz, M., Schapiro, J., Martinez, M., Balbiani, G., Castro, M., 2005. Evaluación de la resistencia a los antihelminticos en ruminates en Argentina. En Resistencia a los Antiparasitarios Internos en la Argentina, Estudio FAO Producción y Sanidad Animal, Organización de las Naciones Unidas para la Agricultura y la Alimentación, Roma 2005. 
Eady, S.J., Woolaston, R.R., Mortimer, S.I., Lewer, R.P., Raadsma, H.W., Swan, A.A., Ponzoni, R.W., 1996. Austr. J. Agric. Res. 47, 895-915.

Echevarria, F.A.M., Gettinby, T.G., Hazelwood, S., 1993. Model predictions for anthelmintic resistance amongst Haemonchus contortus populations in southern Brazil. Vet. Parasitol. 47, 315-325.

Gettinby, G., 1989. Computational veterinary parasitology with an application to chemical resistance. Vet. Parasitol. 115, 167-184.

Gordon, H.McL., 1948. The epidemiology of parasitic diseases, with special reference to studies with nematode parasites of sheep. Austr. Vet. J. 24, 17-44.

Gordon, H.McL., 1981. Epidemiology of helminthosis of sheep: diagnosis. In: Refresher Course for Veterinarians. Proc. 58. Refresher Course for Sheep. University of Sydney (The Post-Graduate Committee in Veterinary Science), 607-615.

Grace, D., Himstedt, H., Sidibe, I., Randolph, T., Clausen, P.H., 2007. Comparing FAMACHA eye colour chart and Haemoglobin Color Scale tests for detecting anaemia and improving treatment of bovine trypanosomosis in West Africa. Vet. Parasitol. 147, 26-39.

Greiner, M., Pfeiffer, D., Smith, RD., 2000. Principles and practical application of the Receiver-Operating Characteristic analysis for diagnostic tests. Pr. Vet. Med. 45, 23-41.

Healey, A.F., Hall, E., Gaden, C.A., Scott, J.M., Walkden-Brown, S.W., 2004. Intensive rotational grazing reduces nematode faecal egg counts in sheep on Cicerone Project. Anim. Prod. Austr. 25, 85-88.

Horak, I.G., 1981. Host specificity and the distribution of the helminth parasites of sheep, cattle, impala and blesbok according to climate. J. S. Afr. Vet. Assoc. 52, 201-206. 
Horak, I.G., Knight, M.M., Williams, E.J., 1991. Parasites of domestic and wild animals in South Africa. XXVIII. Helminth and arthropod parasites of Angora goats and kids in Valley Bushveld. Onderstepoort J. Vet. Res. 58, 253-260.

Horak, I.G., Louw, J.P., 1977. Parasites of domesticated and wild animals in South Africa. IV. Helminths in sheep on irrigated pasture on the Transvaal highveld. Onderstepoort J. Vet. Res. 44, 261-270.

Horak, I.G., MacIvor, K.M. de F., Greeff, C.J., 2001. Parasites of domestic and wild animals in South Africa. XXXIX. Helminth and arthropod parasites of Angora goats in the southern Karoo. Onderstepoort J. Vet. Res. 68, 27-35.

Hoste, H., Jackson, F., Athanasiadou, S., Thamsborg, S.M., Hoskin, S.O., 2006. The effects of tannin-rich plants on parasitic nematodes in ruminants. Trends Parasitol. $22,253-260$.

Ikeme, M.M., Iskander, F., Chong, L.C., 1987. Seasonal changes in the prevalence of Haemonchus and Trichostrongylus hypobiotic larvae in tracer goats in Malaysia. Trop. Anim. Hlth Prod. 19, 184-190.

Karlsson, L.J.E., Greeff, J.C., 2006. Selection response in fecal worm egg counts in the Rylington Merino parasite resistant flock. Aust. J. Exp. Agric. 46, 809-811.

Kenyon F., Greer A.W., Coles G., Cringoli G., Papadopoulos E., Cabaret J., Berrag B., Varady M., Van Wyk J.A., Thomas E., Vercruysse J., Jackson F., 2009. Refugiabased approaches to the control of gastrointestinal nematodes of small ruminants. Vet. Parasitol., in press.doi:10.1016/j.vetpar.2009.04.015.

Kirkman, K.P., Moore, A., 1995. Veld management strategies for livestock farmers in the sourveld regions of South Africa. Bull. Grassland Soc. S. Afr., 6, 25-28. 
Lawrence, K.E., Leathwick, D.M., Rhodes, A.P., Jackson, R., Heuer, C., Pomroy, W.E., Waghorn, T.S., Moffat, J.R., 2007 Management of gastrointestinal nematode parasites on sheep farms in New Zealand. N. Z. Vet. J. 55, 228-234, 2007.

Learmount, J., Taylor, M.A., Smith, G., Morgan, C., 2006. A computer model to simulate control of parasitic gastroenteritis in sheep on UK farms. Vet. Parasitol. 142, 312329.

Levine, N.D., 1980. Nematode parasites of domestic animals and of man. Burgess Publishing, Minneapolis.

Mahieu, M., Arquet, R., Kandassamy, T., Mandonnet, N., Hoste, H., 2007. Evaluation of targeted drenching using FAMACHA $^{\circledR}$ method in Creole goat : Reduction of anthelmintic use, and effects on kid production and pasture contamination. Vet. Parasitol. 146, 135-147.

Malan, F.S., Horak, I.G., De Vos, V., Van Wyk, J.A., 1997. Wildlife parasites: lessons for parasite control in livestock. Vet. Parasitol. 71, 137-153.

Malan, F.S., Van Wyk, J.A., 1992. The packed cell volume and colour of the conjunctivae as aids for monitoring Haemonchus contortus infections in sheep. Proc. S. Afr. Vet. Assoc. Bienn. Nat. Vet. Congr., Grahamstown, 139.

Malan, F.S., Van Wyk, J.A., Wessels, C.D., 2001. Clinical evaluation of anaemia in sheep: early trials. Onderstepoort J. Vet. Res. 61, 165-174.

Martin, P.J., 1989. Selection for thiabendazole resistance in Ostertagia spp. by low efficiency anthelmintic treatment. Internat. J. Parasitol. 19, 317-325.

Martin, P.J., Le Jambre, L.F., Claxton, J.H., 1981. The impact of refugia on the development of thiabendazole resistance in Haemonchus contortus. Internat. J. Parasitol. 11, 35-41. 
McCulloch, B., Kuhn, H.G., Dalbock, R.R., 1984. The relation of climate and topography to worm egg counts of gastro-intestinal nematodes of sheep in the Eastern Cape. Onderstepoort J. Vet. Res. 51, 223-238.

Molento, M.B., Van Wyk, J.A., Coles, G.C., 2004. Sustainable worm management. Vet. Rec., 155, 95-96.

Mönnig, H.O., 1950. Veterinary Helminthology and Entomology ( $3^{\text {rd }}$ Ed.). Baillière, Tindall \& Cox, London.

Moore, A., Van Wyk, J.A., 1997. Weidingsbestuur en haarwurmbeheer by skape. Goue Vag, June 1997, 6-7.

O’Connor, L.J., Kahn, L.P., Walkden-Brown, S.W., 2007. The effects of amount, timing and distribution of simulated rainfall on the development of Haemonchus contortus to the infective larval stage. Vet. Parasitol. 146, 90-101.

Paton, G., Thomas, R.J., Waller, P.J., 1984. A prediction model for parasitic gastroenteritis in lambs. Internat. J. Parasitol. 14, 439-445.

Reynecke, D.P., 2007. Software-based decision-support: a basis for the development of a predictive system for sustainable management of haemonchosis in small ruminants. Thesis, University of Pretoria

Reynecke, D.P., Van Wyk, J.A., Gummow, B., Dorny, P., Boomker, J., 2009a. Validation of the FAMACHA $^{\circledR}$ eye colour chart using sensitivity/specificity analysis on two South African sheep farms. Vet. Parasitol., in press, doi:10.1016/j.vetpar.2009.08.023.

Reynecke, D.P., Van Wyk, J.A., Gummow, B., Dorny, P., Boomker, J., 2009b. A stochastic model accommodating the FAMACHA $^{\circledR}$ system for estimating worm burdens and associated risk factors in sheep naturally infected with Haemonchus contortus. Vet. Parasitol. [Submitted, presently under review] 
Reynecke, D.P., Van Wyk, J.A., Gummow, B., Dorny, P., Boomker, J., 2009c. Use of Receiver Operating Characteristic curves for selection of treatment thresholds using the FAMACHA ${ }^{\odot}$ diagnostic system for anaemia in sheep. Vet. Parasitol., Submitted [Resubmitted, after reviewers' comments and requests had been attended to]

Rhodes, A.P., Leathwick, D.M., Pomroy, W.E., West, D.M., Jackson R., Lawrence, K., Moffat, J., Waghorn, T.S., 2006. A profile of anthelmintic resistance and parasite control practices in New Zealand - results from a 2005 survey. Proc. N. Z. Soc. Anim. Prod. 66, 14-19.

Riley, D.G., Van Wyk, J.A., 2009. Genetic parameters for FAMACHA ${ }^{\odot}$ score and related traits for host resistance/resilience and production at differing severities of worm challenge in a Merino flock in South Africa. Vet. Parasitol., in press, doi:10.1016/j.vetpar.2009.04.014.

Rose, J.H., 1970. Parasitic gastroenteritis in cattle: factors influencing the time of the increase in the worm population on pastures. Res. Vet. Sci. 11, 199-208.

Rossiter, L.W., 1961. Helminth research in South Africa II. Seasonal incidence of nematode parasites of small stock in the Grahamstown area. J. S. Afr. Vet. Med . Assoc. 32, 157-162.

Shannon, C.E., 1948. A mathematical theory of communication. The Bell System Technical Journal, 27, 379-423.

Smith, G., Grenfell, B.T., 1994. Modeling of parasite populations: gastrointestinal nematode models. Vet. Parasitol. 54, 127-143.

Thomas, R.J., 1968. The epizootiology of nematode parasites of sheep in the highveld. (1) Worm egg counts in lambs. J. S. Afr. Vet. Med. Assoc. 39, 27-31. 
Van Wyk, J.A., 1990. Occurrence and dissemination of anthelmintic resistance in South Africa, and management of resistant worm strains. In: Boray, J.C., Martin, P.J., Roush, R.T. (ed). Resistance of Parasites to Antiparasitic Drugs. Round Table Conference, $7^{\text {th }}$ Internat. Congr. Parasitol., Paris, 103-113.

Van Wyk, J.A., 2001. Refugia - overlooked as perhaps the most potent factor concerning the development of anthelmintic resistance. Onderstepoort J. Vet. Res. 68, 55-67. Van Wyk, J.A., 2002. Principles for the use of macrocyclic lactones to minimise selection for resistance. Austr. Vet. J. 80, 437-438.

Van Wyk, J.A., 2003. Think refugia or lose the battle against drug resistance. In Proc. $\mathrm{V}^{\text {th }}$ Internat. Sem. Anim. Parasitol., October 1-3, 2003, Merida, Yucatan, Mexico, 3947.

Van Wyk, J.A., 2006. Face facts : drenching with anthelmintics for worm control selects for worm resistance - and no excuses! Proc. N. Z. Soc. Anim. Prod. 66, 4-13. Van Wyk, J.A., Bath, G.F., 2002. The FAMACHA ${ }^{\circledR}$ system for managing haemonchosis in sheep and goats by clinically identifying individual animals for treatment. Vet. Res. 33, 509-529.

Van Wyk, J.A., Bath, G.F., Groeneveld, H.T., Stenson, M.O., Malan, F.S., 2001. Extensive testing of the $\mathrm{FAMACHA}^{\circledR}$ system for accuracy of clinical evaluation of anaemia caused by ovine haemonchosis. Proc. $5^{\text {th }}$ Internat. Sheep Vet. Congr., Stellenbosch, South Africa, 21-25 January 2001.

Van Wyk, J.A., Hoste, H., Kaplan, R.M., Besier, R.B., 2006. Targeted selective treatment for worm management - how do we sell rational programs to farmers? Vet. Parasitol. 139, 336-346. 
Van Wyk, J.A., Malan, F.S., Randles, J.L., 1997. How long before resistance makes it impossible to control some field strains of Haemonchus contortus in South Africa with any of the anthelmintics? Vet. Parasitol. 70, 111-122.

Van Wyk, J.A., Stenson, M.O., Van der Merwe, J.S., Vorster, R.J., Viljoen, P.G., 1999. Anthelmintic resistance in South Africa: Surveys indicate an extremely serious situation in sheep and goat farming. Onderstepoort J. Vet. Res. 66, 273-284.

Van Wyk, J.A., Van Schalkwyk, P.C., Bath, G.F., Gerber, H.M., Alves, R.M.R., 1991. Die gevaar van wye verspreiding van weerstandbiedendheid teen wurmmiddels deur veldramprestasietoetssentra/The threat of wide dissemination of anthelmintic resistance by veld ram performance testing units. Tydskr. S.-Afr. Vet. Verenig./J. S. Afr. Vet. Assoc. 62, 171-175.

Van Wyk, J.A., Van Schalkwyk, P.C., Gerber, H.M., Visser, Evelyn L., Alves, Regina M.R., Van Schalkwyk L., 1989. South African field strains of Haemonchus contortus resistant to the levamisole/morantel group of anthelmintics. Onderstepoort J. Vet. Res. 56, 257-262.

Vatta, A.F., Letty, B.A. Van der Linde, M.J., Van Wijk, E.F., Hansen, J.W., Krecek, R.C., 2001. Testing for clinical anaemia caused by Haemonchus spp. in goats farmed under resource-poor conditions in South Africa using an eye colour chart developed for sheep. Vet. Parasitol. 99, 1-14.

Vatta, A.F., Lindberg, A.L.E., 2006. Managing anthelmintic resistance in small ruminant livestock of resource-poor farmers in South Africa. J. S. Afr. Vet. Assoc. 77, 2-8. Veglia, F., 1915. Anatomy and life-history of the Haemonchus contortus (Rud). Union of South Africa. Dept. Agric. $3^{\text {rd }} \& 4^{\text {th }}$ Reports Dir. Vet. Res., 347-500. 
Waghorn, T.S., Leathwick, D.M., Rhodes, A.P., Jackson, R., Pomroy, W.E., West, D.M., Moffat, J.R., 2006. Prevalence of anthelmintic resistance on 62 beef cattle farms in the North Island of New Zealand. N. Z. Vet. J. 54, 278-282.

Waller, P.J., 1997. Anthelmintic resistance. Vet. Parasitol. 72, 391-412.

Waller, P.J., 2003. The future of anthelmintics in sustainable parasite control programs for livestock. Helminthologia 40, 97-102. 